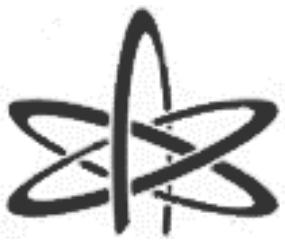

BJRS

\author{
BRAZILIAN JOURNAL \\ $\mathrm{OF}$ \\ RADIATION SCIENCES \\ 06-02 (2018) 01-11
}

\title{
The recycling through melting Zircaloy machining chips,
} preliminary results

\author{
Luiz A. T. Pereira ${ }^{\mathrm{a}}$ and Jesualdo L. Rossi ${ }^{\mathrm{a}}$ \\ ${ }^{a}$ Materials Science and Technology Center - CCTM \\ Nuclear and Energy Research Institute (IPEN - CNEN/SP) \\ Av. Prof. Lineu Prestes, 2242 - CEP 05508-000 - São Paulo, SP - Brazil \\ luiz.atp@uol.com.br,jelrossi@ipen.br
}

\begin{abstract}
PWR (Pressurized Water Reactor) reactors employ as nuclear fuel $\mathrm{UO}_{2}$ pellets packed in zirconium alloy tubes, called cladding. In the manufacture of the tubes, machining chips are generated which can not be discarded, since the recycling of this material is strategic in terms of nuclear technology, legislation, economics and the environment. These nuclear alloys are very expensive and are not produced in Brazil and are imported for the manufacture of nuclear fuel. In this work, we will discuss methods not yet studied to recycle Zircaloy chips using electron beam furnaces in order to obtain ingots. In addition, it is intended to carry out the melting of new Zircaloy alloys, from the fusion of zirconium sponge produced in IPEN and imported and Zircaloy bars. The mechanical properties and the present phases of the material should be determined, as well as, the characterization of the microstructures by optical microscopy. This work, therefore, aims at the creation of a new line of research where methods will be approached to recycle the chips and to reduce in 30 times by means of fusion the enormous volume of material stored in the form of machining chips, being able to do others components for nuclear or chemical industry use, as well as conducting basic development research.
\end{abstract}

Keywords: Zircaloy, nuclear fuel, recycling, cladding, electron beam melting 


\section{INTRODUCTION}

Zirconium alloys have been used more extensively in the nuclear industry because of their low shock section for neutron absorption compared to other structural materials [1]. Among these alloys are those known as Zircaloy-4, being mainly applied in the fuel elements of the PWR (Pressurized Water Reactor) type power reactors, which are constituted by an organized set of tubes, where the $\mathrm{UO}_{2}$ pellets are packaged. The tubes are called cladding.

Each rod is closed at its ends by a plug, also made in Zircaloy, which also has the function of supporting the rod when it is lifted for assembly. These caps, known as end-caps, are produced from solid Zircaloy bars. During the manufacture of these components large amounts of chips are generated, resulting from the machining of the parts on automatic mechanical lathes.

The zirconium-based alloys comply with nuclear requirements due to the excellent mechanical properties, corrosion resistance and low absorption cross-section for thermal neutrons [2]. These properties are obtained due to the low hafnium content in the alloys and appropriate chemical compositions and microstructures. The most common alloys are called Zircaloy-2, Zircaloy-4, Zirlo® and M5®, whose elemental of Zircaloy-4 composition are shown in Table 1.

Table 1: Typical composition of Zircaloy-4 [3,4].

\begin{tabular}{lllllll}
\hline $\begin{array}{l}\text { Element } \\
(\text { mass \%) }\end{array}$ & Sn & Fe & Cr & O & Hf & Zr \\
\hline Zircaloy-4 & $1.2-1.7$ & $0.18-0.24$ & $0.07-0.13$ & 0.12 & $<1000$ ppm & balance \\
\hline
\end{tabular}

Nuclear grade zirconium alloys are considered strategic materials. Therefore, besides its high cost, it is not freely commercialized. Consequently, the production of $\mathrm{Zr}$ alloys is a requirement for the autonomous domain of the process of nuclear power generation and the Zircaloy machining chips are a valuable source of nuclear zirconium. Zircaloy chips have a potential value estimated at US\$ 78/kg [4,5], since the Zr metal is the major constituent of Zircaloy (Zry-4 for short) alloy with the great advantage of being $\mathrm{Hf}$ free [6,7]. 
Brazil has the technology for the production of nuclear fuel from the uranium mining to manufacturing and assembling of fuel elements, including the isotopic enrichment process [8]. However, the production of zirconium alloys is not carried out in the country at industrial scale and as consequence, the $\mathrm{Zr}$ alloys in its nuclear power plants is imported.

\section{MATERIALS AND METHODS}

Because the machining process employs a cooling fluid containing oil, it needs to be eliminated. For this, the chips were subjected to a cleaning step performed by washing for degreasing and pickling, followed by washing. Pickling was carried out in two steps of aqueous solutions: one with $\mathrm{HCl}$ $\left(50 \mathrm{HCl}: 50 \mathrm{H}_{2} \mathrm{O}\right)$ and one with $\mathrm{HNO}_{3}\left(30 \mathrm{HNO}_{3}: 70 \mathrm{H}_{2} \mathrm{O}\right)$.

An electron beam melting (EB) was used to melt the Zircaloy chips. This equipment belongs to the IPT (Institute of Technological Research of São Paulo) and a partnership was made with IPEN. After vacuuming, the electron beam (approximately $10 \mathrm{~mm}$ diameter) was formed and the $220 \mathrm{~g}$ charge of Zry-4 chips was melted in the water-cooled copper crucible, giving rise to a button with $66 \mathrm{~mm}$ in diameter and $14 \mathrm{~mm}$ thick.

The heat treatment was carried out in order to verify the influence of temperature on the Zry-4 mechanical and microstructural properties, since several studies [8-10] show very important changes in mechanical resistance, aiming to observe the presence and behavior of the phase beta in the microstructure. The heat treatments performed involved four treatment conditions: annealing, quenching, aging at $500{ }^{\circ} \mathrm{C}$ and aging at $700{ }^{\circ} \mathrm{C}$.

Using the electrical discharge machining, cylindrical bars were removed from the molten button, as is shown in Figure 1. Then the bars were machined to the dimensions of sub-size specimens for the mechanical tests, including tensile test (according to ASTM [10]) and hardness test (Rockwell B $\left.\mathrm{HR}_{\mathrm{B}}\right)$.

In order to avoid specimens oxidation they were protected during the heat treatments by means of quartz encapsulation with argon atmosphere. The heat treatment was carried out in a mufle type furnace. First, the encapsulated samples were subjected to heating at $950{ }^{\circ} \mathrm{C}$, with a 2-hour level temperature with 3 samples, rapid cooled in water (quenching). The remaining specimen was kept 
inside the oven for slow cooling (annealing). After, one encapsulated sample was treated in the oven set at $500{ }^{\circ} \mathrm{C}$ and the other at $700{ }^{\circ} \mathrm{C}$, with a 1-hour level and air-cooled.

Figure 1: a) molten button; b) specimens for tensile testing; c) specimens adapter to the testing machine.

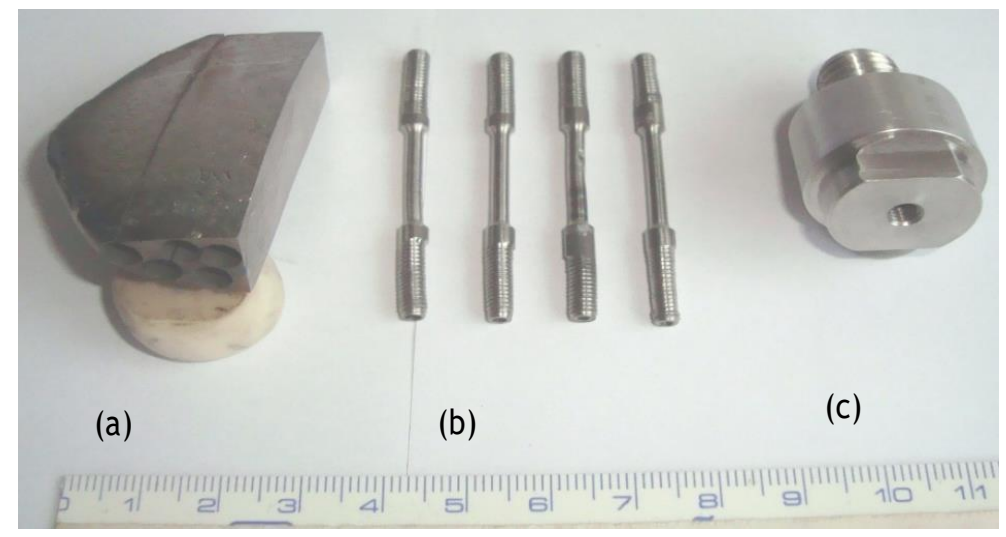

Source: Luiz A. T. Pereira

The samples for microstructural analysis were removed from the cast materials by precision diamond cutting and embedded in cold curing polyester resin and subjected to grinding on $\mathrm{SiC}$ sands with 400, 600, 1200, 2400 and 4000 grain size.

The preparation was sequenced with $6 \mu \mathrm{m}$ diamond paste metallographic polishing, followed by 1 $\mu \mathrm{m}$ diamond paste and finally with $0.06 \mu \mathrm{m}$ colloidal silica. The attack was performed with a solution of $50 \% \mathrm{H}_{2} \mathrm{O}_{2}+25 \% \mathrm{HNO}_{3}+25 \%$ ethyl alcohol $+2 \mathrm{HF}$ drops [11].

The Zircaloy microstructural analyzes were carried out in both in the raw state and in the samples submitted to the heat treatment and were did by optical microscopy with image analysis software.

\section{RESULTS AND DISCUSSION}

It is shown in Figure $2(a, b)$ the Zry- 4 melted button by the electron beam method. 
Figure 2: a) Upper face; b) lower face of the Zry-4 melted button.
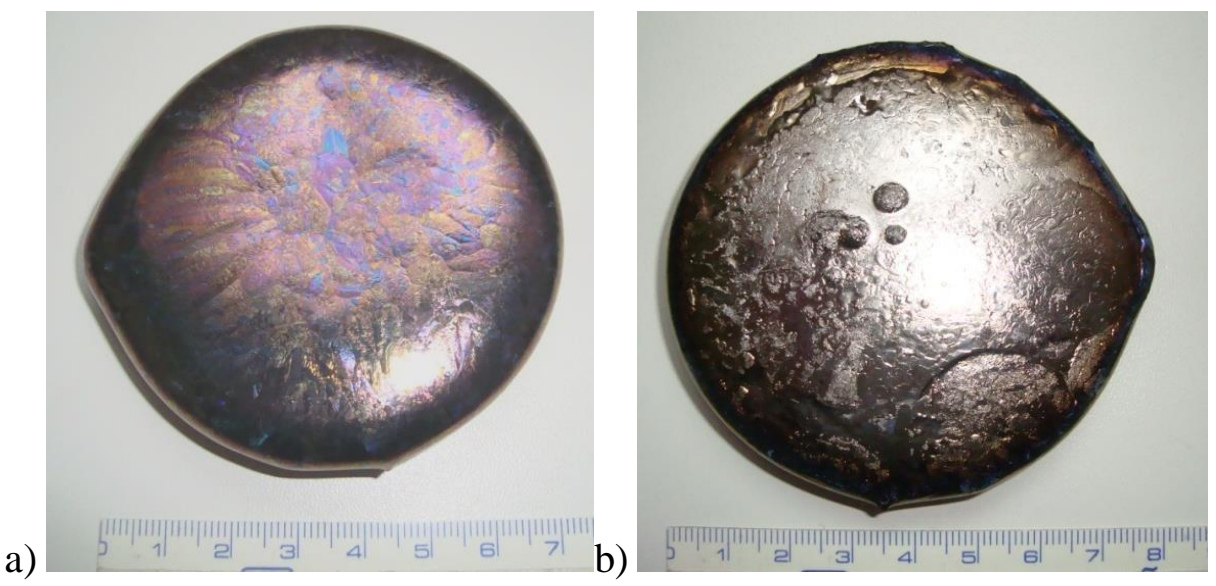

Source: Luiz A. T. Pereira

In Figures 3 and 4 are shown the stress $x$ strain curves of the heat treated samples and in the Table 2 it is possible to verify the values obtained of the mechanical properties of the Zry-4 obtained by the electron beam melting.

Figure 3: Stress $x$ engineering deformation curve of annealed the sample and subjected to slow cooling.

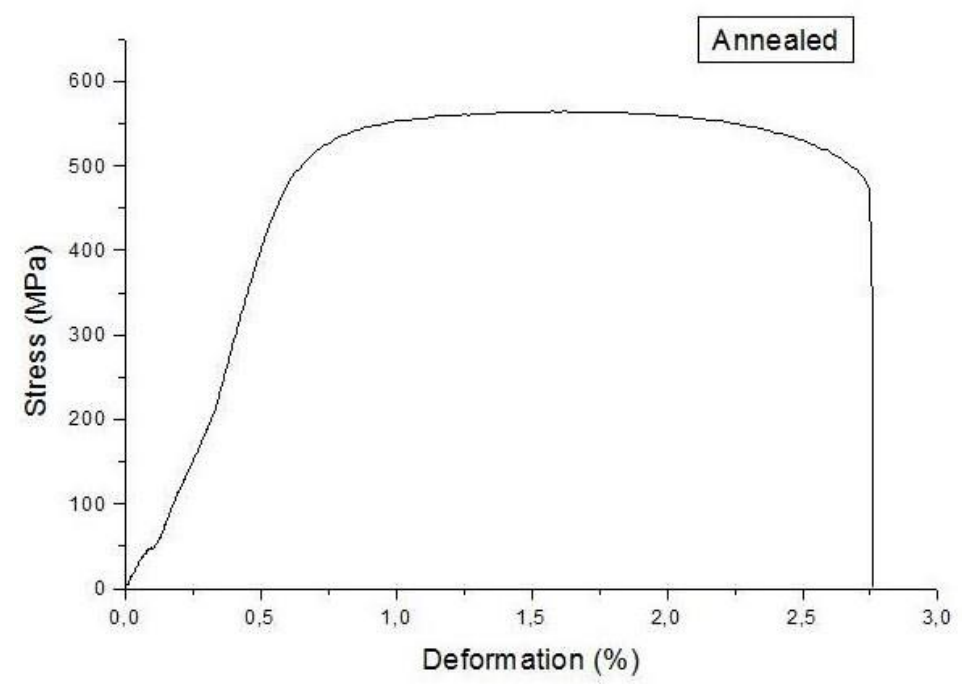

Source: Luiz A. T. Pereira 
Figure 4: Stress curve $x$ engineering deformation curve of the sample subjected to aging treatment at $500{ }^{\circ} \mathrm{C}$.

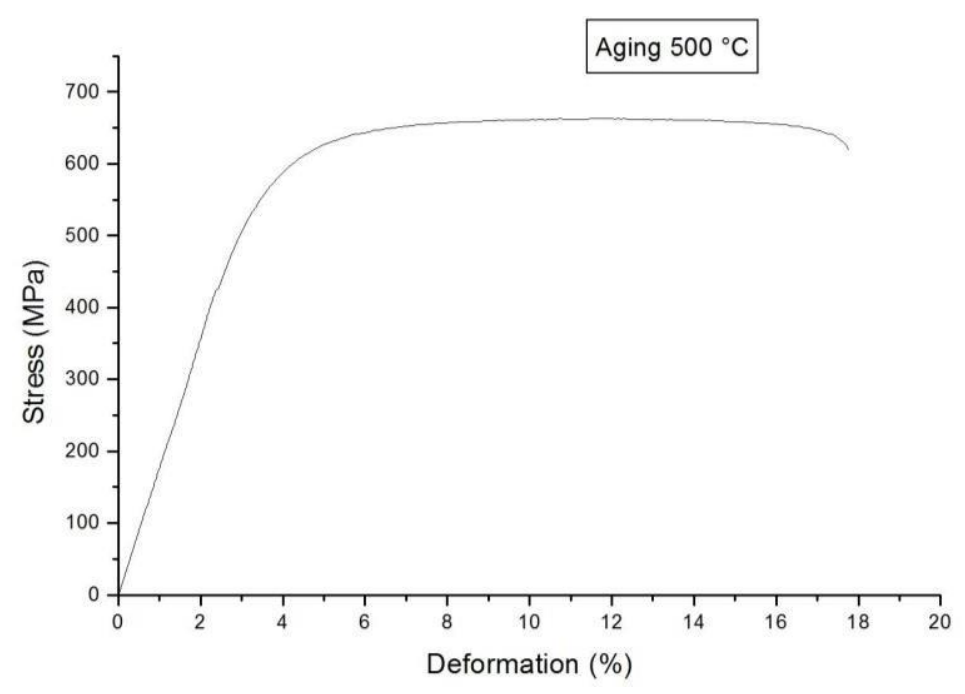

Source: Luiz A. T. Pereira

Table 2: Mechanical properties of Zircaloy-04 (tensile strength and deformation) obtained by the electron-beam melting method.

\begin{tabular}{cccccc}
\hline Heat treatment & $\begin{array}{c}\text { Tensile strength } \\
(\mathrm{MPa})\end{array}$ & $\begin{array}{c}\text { Deformation } \\
(\%)\end{array}$ & $\begin{array}{c}\text { Tensile strength } \\
\text { ASTM (MPa) }\end{array}$ & $\begin{array}{c}\text { Deformation } \\
\text { ASTM (\%) }\end{array}$ & $\begin{array}{c}\text { Hardness } \\
\text { HR }_{\mathrm{B}}\end{array}$ \\
\hline Annealed & 562 & 12.9 & 385 & 18 & 69 \\
\hline Quenched & - & 13.3 & - & - & 69 \\
\hline Aging $500{ }^{\circ} \mathrm{C}$ & 662 & 14.2 & - & - & 62 \\
\hline Aging $700{ }^{\circ} \mathrm{C}$ & 357 & 0 & - & \\
\hline
\end{tabular}

The image of Figure 5 is related to the sample of the die cut sheet of the Zircaloy- 4 molten button obtained by the electron beam method, and the typical microstructure of the material in the raw state of melting can be observed. 
In the Figures 6 and 7 can observed the microstructure of the samples that were submitted at heat treatments mentioned above.

Figure 5: Zircaloy-4 microstructure obtained by the electron-beam melting method (raw state) with a Widmanstätten structure characteristic of the basketweave morphology.

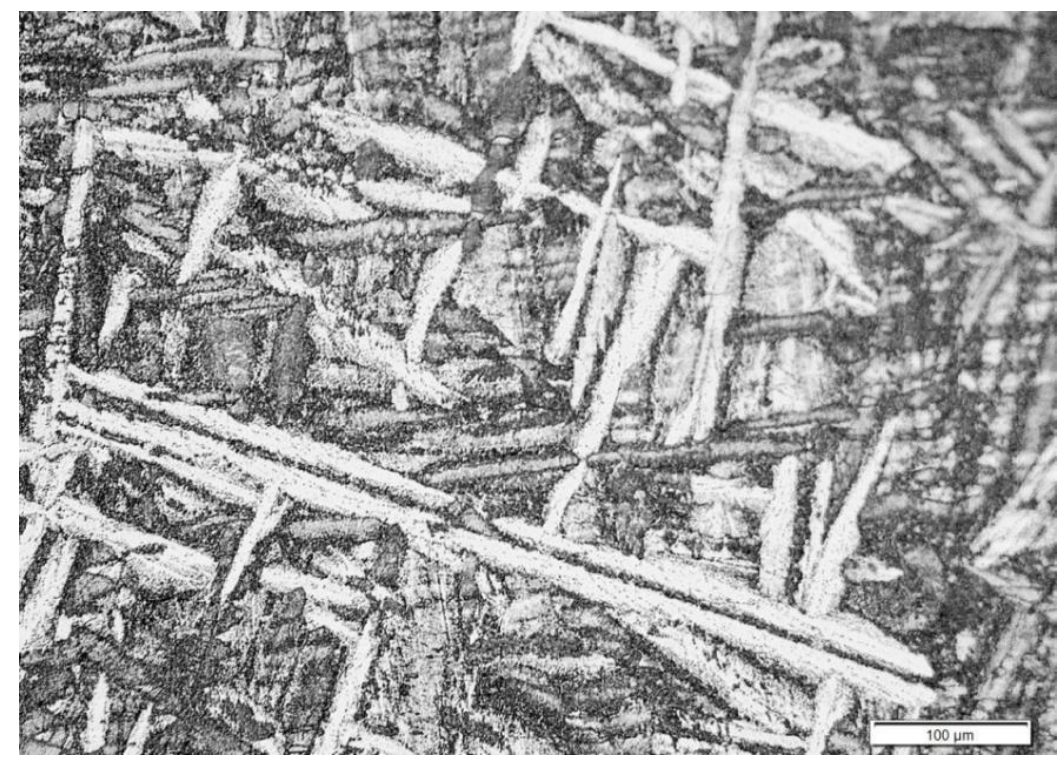

Source: Luiz A. T. Pereira

Figure 6: Zircaloy-4 microstructure treated with annealing showing characteristic morphology of Widmanstätten structure of basketweave form. 


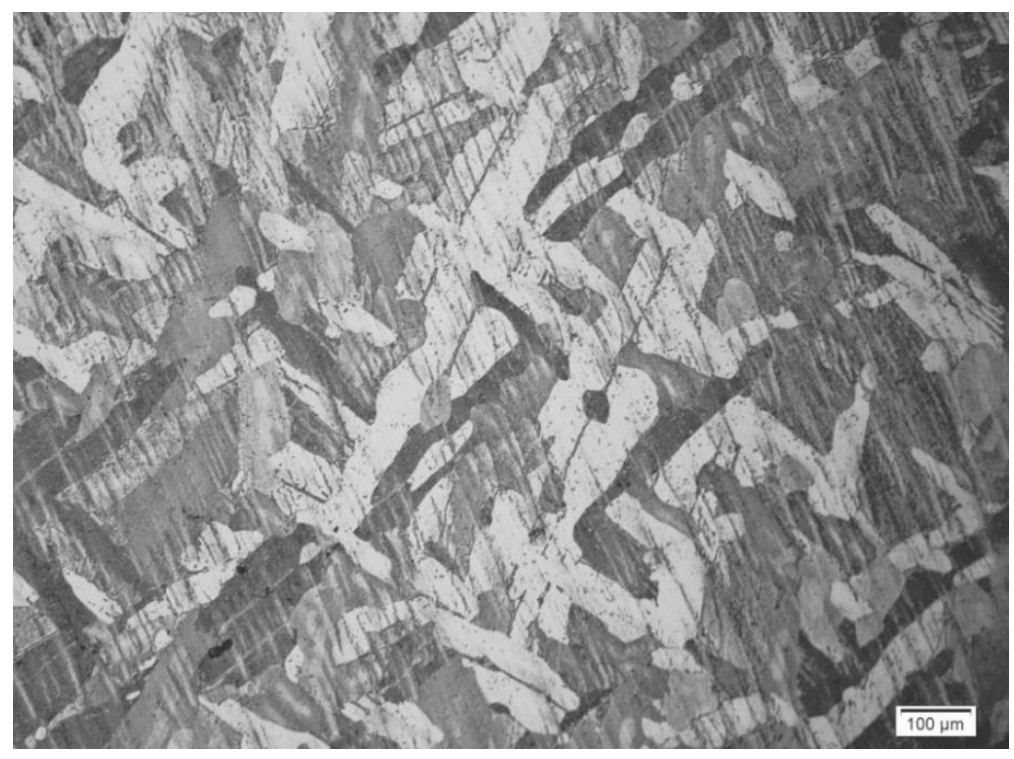

Source: Luiz A. T. Pereira

Figure 7: Zircaloy-4 microstructure aged at $500{ }^{\circ} \mathrm{C}$ with the same previous morphology but different arrangement.

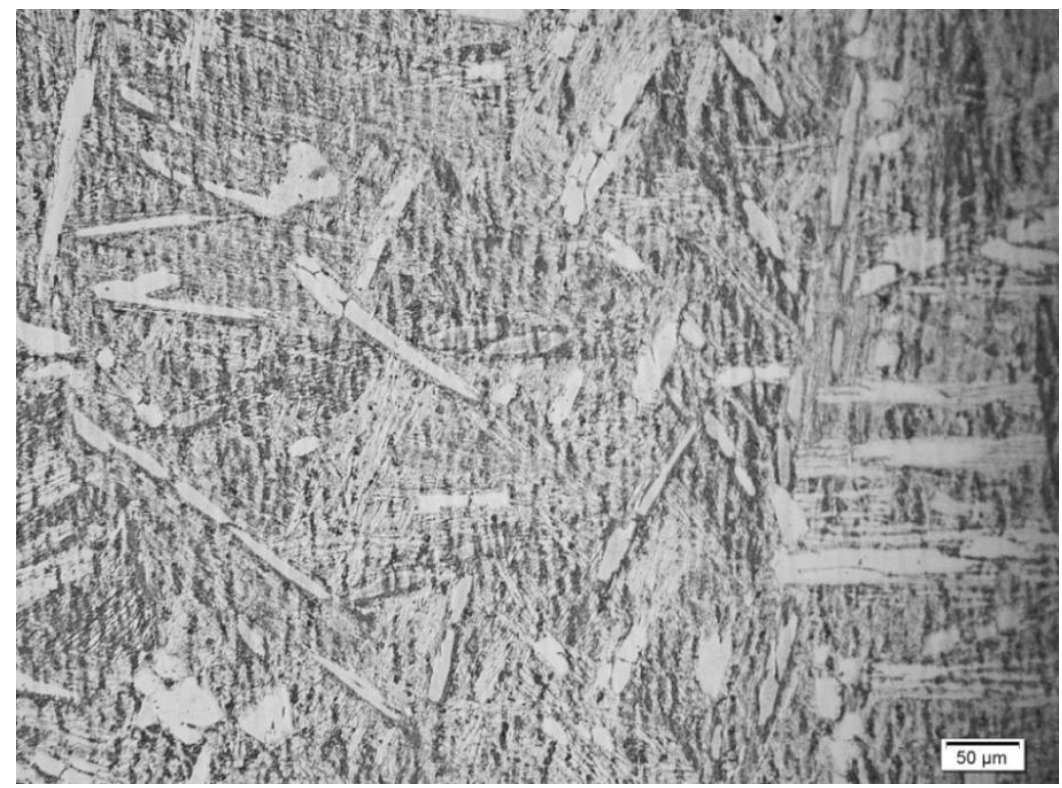

Source: Luiz A. T. Pereira

Regarding the mechanical properties, the strenght limit is above the ASTM specification, while the deformation is in the same range and can be considered satisfactory. It can be observed that there 
was an increase of the tensile strength and the deformation when the material is in the aged state. Besides that, there was an increase of the hardness when the material was quenched but the annealing at didn't have any effect and at $700{ }^{\circ} \mathrm{C}$ decreased the hardness.

The microstructures analyzed by optical microscopy have the characteristic aspect of those found in the literature [13], however it is interesting to confirm by means of EDS scanning electron microscopy the present phases and to identify some found precipitates, such as those that appear in the microstructures of the sample aged at $500{ }^{\circ} \mathrm{C}$ (Fig. 7). The appearance of these microstructures is consistent with the heat treatments, that is, the annealing has led to the thickening of the Widmanstätten slats in the microstructure and the aging has led to the phases coalescence.

\section{CONCLUSION}

The methods selected for the melting through the electron beam (EB) were effective to obtain a homogenous material with characteristics considered appropriate and was fast as a function of the amount of charge placed which took approximately 5 min to melt, besides an efficient vacuum system, causing little oxidation to the material.

The preliminary results up to the present moment of the project have shown positive in function of the obtained properties, taking as reference the values of mechanical strength of the ASTM standard. Other studies are in development, such as microstructural research using scanning and transmission electron microscopy to verify the presence of second phase particles [9] in the microstructure of the material and its influence on the hot and cold lamination in strips taked of the molten button. In addition, the objective is to verify the thermo-mechanical and flow behavior of the molten material by the electron beam method.

\section{ACKNOWLEDGMENT}

The authors thank: INB (Nuclear Industries of Brazil S.A.) for providing the machining chips and to the CNPq for awarding a post doctorate scholarship to the author. To Daniel Leal and Eduardo J. Nogueira for the melting in electron beam and sample preparation, respectively. 


\section{REFERENCES}

1. MUKHERJEE, P.; SARKAR, A.; BARAT, P.; BANDYOPADHYAY, S.K. et al. Microstructural studies on lattice imperfections in deformed zirconium-base alloys by X-ray diffraction. Metallurgical Materials Trans. v. 31A, p. 2405-9, 2000.

2. STEINBRÜCK, M. Hydrogen absorption by zirconium alloys at high temperatures. Journal of Nuclear Materials, v. 334(1), p. 58-64, 2004. Available from: http://linkinghub.elsevier.com/retrieve/pii/S0022311504004799

3. Standard specification for hot-rolled and cold-finished zirconium and zirconium alloy bars, rod, and wire for nuclear application. ASTM: B351-08. ASTM-American Soc. Testing Materials.

4. YILMAZBAYHAN, A.; MOTTA, A.T.; COMSTOCK, R.J. et al. Structure of zirconium alloy oxides formed in pure water studied with synchrotron radiation and optical microscopy: relation to corrosion rate. Journal of Nuclear Materials, v. 324(1), p.6-22, 2004.

5. DAYTON, R.W.; ALLEN, C.M.; EBERTS, W.U. The reclamation of zirconium machining chips to produce arc-melting feed stock. United States at Energy Comm.; AECD-3499, 1952.

6. MIMURA, K.; LEE, S-W.; ISSHIKI, M. Removal of alloying elements from zirconium alloys by hydrogen plasma-arc melting. Journal of Alloys Compounds, v. 221(1-2), p. 267-73, 1995. Available from: http://linkinghub.elsevier.com/retrieve/pii/0925838894014701.

7. BOHE, A.E.; ANDRADE GAMBOA, J.J.; LOPASSO, E.M.; PASQUEVICH, D.M. Zirconium recovery from Zircaloy shavings. Journal of Material Science, v. 31, p. 3469-74, 1996.

8. PEREIRA, L.A.T. Desenvolvimento de processos de reciclagem de cavacos de zircaloy via refusão em forno elétrico a arco e metalurgia do pó. Nuclear and Energy Research Institute IPEN. Tese., 2014.

9. MENG, X.; NORTHWOOD, D. Second phase particles in Zircaloy-2. Journal of Nuclear Materials; v. 168, p. 125-36, 1989.

10. VIZCAINO, P.; BANCHIK, A.D.; ABRIATA, J.P. Synchrotron X-ray diffraction evidences of the amorphization/dissolution of the second phase particles (SPPs) in neutron irradiated Zircaloy4. Material Letter, v. 62(3), p. 491-3, 2008. 
11. Standard Test Methods for Tension Testing of Metallic Materials - ASTM E8/E8M. ASTMAmerican Soc. Testing Materials. p. 1-27, 2009.

12. VANDER VOORT, G.F. Metallography - Principles and Practice. ASM International, 1999.

13. DANIELSON, P.E. and SUTHERLIN, R.C. Metallography and microstructures of zirconium, hafnium, and their alloys. In: Metallography and Microstructures, ASM Handbook, v. 9, p. 942-958, 2004. 